\title{
STUDY OF KINETICS OF THE OXIDATION OF LEVULINIC ACID BY Ce (IV)-PERCHLORATES IN PERCHLORIC ACID
}

\section{RAJESH SHUKLA", SUSHMA RANI2 AND TEWARI I.C.1*}

\author{
1Department of Chemistry, D.B.S. P.G. College, Kanpur, India \\ 2Department of Chemistry, D.G. P.G. College, Kanpur, India \\ ${ }^{*}$ Corresponding Author: Email- drictiwari@yahoo.co.in
}

Received: May 02, 2012; Accepted: May 10, 2012

\begin{abstract}
The present manuscript deals the kinetics of the oxidation of levulinic acid by $\mathrm{Ce}$ (IV) perchlorates in perchloric acid. The reaction follows a first order rate dependence on the Ce (IV) concentration but the value of $k 1$ decreases with the increasing concentration of Ce (IV). Evidence for complex formation between Ce (IV) and levulinic acid was obtained from the Michaelies-Menten reciprocal plots. This was further confirmed spectrophotometrically where the absorption intensity in the wave length region $212 \mathrm{~m} \mu-216 \mathrm{~m} \mu$, was intensified as compared to absorption spectra of $\mathrm{Ce}(\mathrm{IV})$ perchlorate under identical conditions with an increase in $[\mathrm{H}+]$, the rate increases and a plot between [HClO4 ] -1 and k1-1 is a straight line intercepting the ordinate. The reaction shows a positive salt effect. A suitable mechanism has been postulated and the values of activation parameters are reported.
\end{abstract}

Key words-

Citation: Rajesh Shukla, Sushma Rani and Tewari I.C. (2012) Study of Kinetics of the Oxidation of Levulinic Acid by Ce (IV)-Perchlorates in Perchloric Acid. International Journal of Chemical Research, ISSN: 0975-3699 \& E-ISSN: 0975-9131, Volume 4, Issue 1, pp.-126-129.

Copyright: Copyright@2012 Rajesh Shukla, et al. This is an open-access article distributed under the terms of the Creative Commons Attribution License, which permits unrestricted use, distribution, and reproduction in any medium, provided the original author and source are credited.

\section{Introduction}

The kinetics of the oxidation of various organic compounds by cerium (IV) has been reported by many authors [1-5] but the study in the field of oxidation of ketonic acid is scarce. The existence of the cerium (IV) salts as Ce (IV) acetylacetonate [6], Ce (IV) tetrakis (dibenzoyl methane) [7] and $\mathrm{Ce}$ (IV) disalicylalpropalenediammine [8], the X-rays diffraction studies have clearly indicated that the coordination umber of $\mathrm{Ce}$ (IV) is eight. It seems most likely that the sulphate [9] and nitrate salts which are also eight coordinated, whereby more than one coordination site may be occupied by the oxygen atom of a single nitrate or sulphate ion. In solution, the solvent may occupy the coordination sites so that eight coordinate of $\mathrm{Ce}$ (IV) is maintained. The spectral and potentiometric studies [10-17] of Ce (IV) in perchloric acid have revealed that the $\mathrm{Ce}$ (IV) does not appear to form stable complexes with perchlorate ion but exist as $\left[\mathrm{Ce}\left(\mathrm{H}_{2} \mathrm{O}\right)_{8}\right]^{4+},[\mathrm{Ce}$ $\left.\left(\mathrm{H}_{2} \mathrm{O}\right)_{7} \mathrm{OH}\right]^{3+}$ and $\left[\mathrm{Ce}\left(\mathrm{H}_{2} \mathrm{O}\right)_{6}(\mathrm{OH})_{2}\right]^{2+}$ along with dimeric species Ce$\mathrm{O}-\mathrm{Ce}^{6+}$. On the basis of our experimental findings we propose that the oxidizing species of $\mathrm{Ce}$ (IV) in the oxidation of levulinic acid is $\left[\mathrm{Ce}\left(\mathrm{H}_{2} \mathrm{O}\right)_{8}\right]^{4+}$.

\section{Experimental \\ Material Employed}

Levulinic acid used was E. Merck grade and Ce (IV)-perchlorate was prepared from the analar quality (B.D.H.) of ceric ammonium nitrate. Other reagents were perchloric acid $(60 \%$, Riedel), sodium perchlorate (Riedel), barium perchlorate (E. Merck), sodium hydroxide A.R. (B.D.H), ferrous ammonium sulphate A.R. (B.D.H) and ferroin (E. Merck) grade. The acid strength of the stock solution was determined as described in the literature [18].

To a known volume of perchloric acid and ceric perchlorate which were kept in a thermostat, was added a required volume of levulinic acid which was also kept in the same thermostat. At suitable interval $5.00 \mathrm{ml}$ of the reaction mixture was withdrawn and analyzed for $\mathrm{Ce}$ (IV) after quenching the reaction with a known volume of ferrous ammonium sulphate and titrating the excess of ferrous ion with ceric sulphate solution using ferroin as an indicator. Reaction bottles were painted black to eliminate any photochemical reduction. The rate constant were obtained by potting a graph between time and $\log (a-x)$, the slope gives the value of $k_{1}$. 


\section{Results and Discussion}

The spectrophotometric studies of $\mathrm{Ce}$ (IV) perchlorate in perchloric acid medium suggested that, predominantly, $\mathrm{Ce}$ (IV) species in our experimental conditions was $\left[\mathrm{Ce}\left(\mathrm{H}_{2} \mathrm{O}\right)_{7} \mathrm{OH}\right]^{3+}$. We base our conclusion from the facts that the intensity of the absorption in the wave length region $211 \pm 5 \mathrm{m \mu}$ is maximum and the intensity is drastically cut in this region when the concentration of the $\mathrm{Ce}$ (IV) is increased from $0.62 \times 10^{-3} \mathrm{~N}$ to $6.67 \times 10^{-3} \mathrm{~N}$ at fixed concentration of perchloric acid, indicating that the dimerisation has set in at higher concentration. Because the dimeric species results from the association of monomeric species $\left[\mathrm{Ce}\left(\mathrm{H}_{2} \mathrm{O}\right)_{7} \mathrm{OH}\right]^{3+}$, the decrease in the absorption intensity at the wavelength $211 \pm 5 \mathrm{m \mu}$ justifies absorption region of monomeric species $\left[\mathrm{Ce}\left(\mathrm{H}_{2} \mathrm{O}\right)_{7} \mathrm{OH}\right]^{3+}$. We have also performed the spectrophotometric studies at different $\mathrm{H}^{+}$concentrations at a fixed concentration of $\mathrm{Ce}$ (IV) and have noticed that the intensity in the wavelength region $211 \pm 5 \mathrm{m \mu}$ decreases. It is reported in the literature that the production of hydrolysed ceric species in the perchloric acid medium represented by the following equation (1) will be $85 \%$ complete [15] when the concentration of perchloric acid is kept at $2 \mathrm{M}$.

$$
\left.\mathrm{Ce}\left(\mathrm{H}_{2} \mathrm{O}\right)_{8}\right]^{4+} \leftrightarrow\left[\mathrm{Ce}\left(\mathrm{H}_{2} \mathrm{O}\right)_{7} \mathrm{OH}\right]^{3+}+\mathrm{H}^{+}
$$

In all our experiments the maximum concentration of perchloric acid employed was $1.80 \mathrm{M}$, indicating that $\mathrm{Ce}$ (IV) will mostly occur as $\left[\mathrm{Ce}\left(\mathrm{H}_{2} \mathrm{O}\right){ }_{7} \mathrm{OH}\right]^{3+}$.

The rate of disappearance of $\mathrm{Ce}$ (IV) in perchloric acid medium follows first order kinetics. The value of first order rate constant has been calculated from the slope of the graph between't' and log $(a-x)$. The graph obtained is a straight line indicating that the value of rate constant does not alter during the run. The kinetic results of two typical runs are reproduced in Figure-1. The value of $k_{1}$ depends with the initial concentration of $\mathrm{Ce}$ (IV)-perchlorate.

Table-1 Effect of change of concentration of Ce (IV) on reaction velocity

\begin{tabular}{|lllllll|}
\hline $\left.\mathrm{Ce}\left(\mathrm{ClO}_{4}\right)_{4}\right] \times 10^{3} \mathrm{~N}$ & 1.67 & 1.25 & 1.00 & 0.77 & 0.62 & 0.48 \\
\hline $\mathrm{K}_{1} \times 10^{4} \mathrm{sec}^{-1}$ & 2.285 & 3.030 & 3.535 & 4.407 & 5.011 & 6.322 \\
\hline
\end{tabular}

Temperature $-30^{\circ} \mathrm{C}$, Levulinic acid $]=1.00 \times 10^{-2} \mathrm{M}$ and $\left[\mathrm{HClO}_{4}\right]=$ $0.30 \mathrm{~N}$

The rate of oxidation increases with the $[\mathrm{H}+]$ and the plot of $1 / \mathrm{k} 1$ against $[\mathrm{H}+]-1$ is linear (Figure-2B).

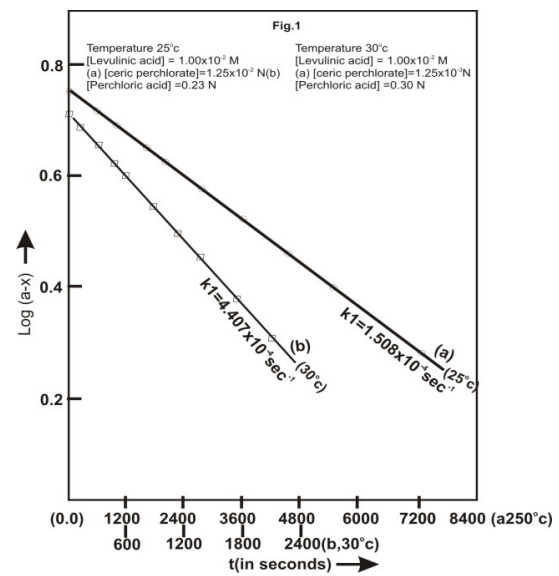

Fig. 2- Plot $A(\bullet)$ the rate dependence on Levulinic Acid concentration $\left[\mathrm{Ce}\left(\mathrm{ClO}_{4}\right)_{4}\right]=1.25 \times 10^{-3} \mathrm{M}$ and $\left[\mathrm{HClO}_{4}\right]=0.20 \mathrm{~N}$

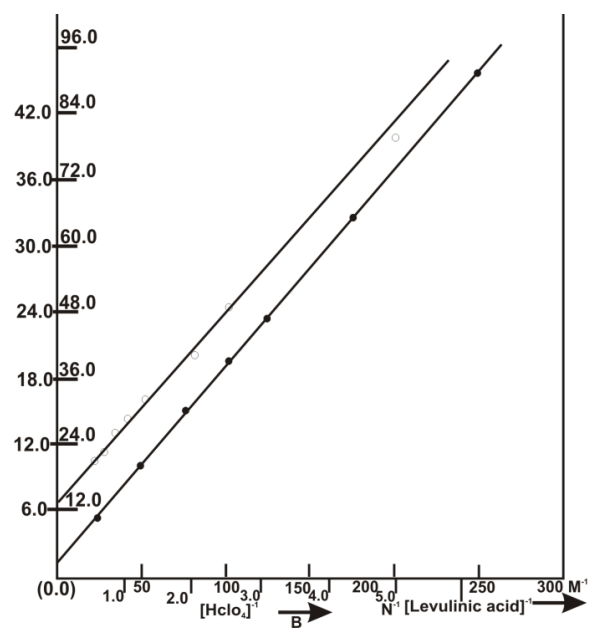

Fig. 2- Plot $B(0)$ the rate dependence on Perchloric Acid concentration $\left[\mathrm{Ce}\left(\mathrm{ClO}_{4}\right)_{4}\right]=1.25 \times 10^{-3} \mathrm{M}$ and $\left[\mathrm{HClO}_{4}\right]=1.00 \times 10^{-3} \mathrm{M}$

The Michaelies-Menten reciprocal plots of $1 / k_{1}$ against $1 /$ [Levulinic acid] is also a straight line cutting an intercept from the ordinate (Figure-2A).This corresponds to complex formation between $\mathrm{Ce}$ (IV) and levulinic acid. This has been further confirmed spectrophotometrically [Perkin Elmer - 202] by taking the absorption spectra of the reaction mixture in the ultraviolet region. The intensification of the absorption intensity in the range $212 \mathrm{m \mu}-216 \mathrm{m \mu}$ occurs as compared to the absorption spectra of $\mathrm{Ce}(\mathrm{IV})$ perchlorate under identical conditions. The observation of absorption spectra of levulinic acid, when recorded separately, eliminates the possibility of its contribution to the above intensification of the absorption intensity. The $\lambda_{\max }$ for levulinic acid has been observed in the range of $267 \pm 3 \mathrm{m \mu}$. The addition of $\mathrm{NaClO}_{4}$ and $\mathrm{Ba}\left(\mathrm{ClO}_{4}\right)_{2}$ produces a positive salt effect. The salt effect is more pronounced in the case of $\mathrm{NaClO}_{4}$ as compared to $\mathrm{Ba}\left(\mathrm{ClO}_{4}\right)_{2}$.

Table-2 Effect of addition of salts on the rate of reaction

\begin{tabular}{|llll}
{$\left[\mathrm{NaClO}_{4}\right] \times \mathrm{N}$} & $\mathrm{K}_{1} \times 10^{4} \mathrm{sec}^{-1}$ & {$\left[\mathrm{Ba}\left(\mathrm{ClO}_{4}\right)_{2}\right] \times 10^{2} \mathrm{M}$} & $\mathrm{K}_{1} \times 10^{4} \mathrm{sec}^{-1}$ \\
0.00 & 2.532 & 0.00 & 2.532 \\
0.25 & 2.897 & 5.00 & 2.519 \\
0.50 & 3.147 & 10.00 & 2.536 \\
0.80 & 3.358 & 15.00 & 2.598 \\
1.00 & 3.550 & 20.00 & 2.617 \\
1.50 & 3.758 & & \\
2.00 & 3.983 & & \\
\hline
\end{tabular}

Temperature $-30^{\circ} \mathrm{C}$, [Levulinic acid $]=1.00 \times 10^{-2} \mathrm{M}$ and $\left[\mathrm{HClO}_{4}\right]=$ $0.20 \mathrm{~N},\left[\mathrm{Ce}\left(\mathrm{ClO}_{4}\right)_{4}\right]=1.25 \times 10^{3} \mathrm{~N}$

The effect of temperature on the rate of reaction and the values of activation parameters are given in Table- 3 .

Table-3 Effect of temperature on the rate of reaction and the values of activation parameters

\begin{tabular}{|lllll|}
\hline Temperature $0^{\circ} \mathrm{C}$ & 25 & 30 & 35 & 40 \\
\hline $\mathrm{K}_{1} \times 10^{4} \mathrm{sec}^{-1}$ & 1.508 & 2.532 & 4.299 & 7.197 \\
\hline
\end{tabular}

[Levulinic acid $]=1.00 \times 10-2 \mathrm{M}$ and $[\mathrm{HClO} 4]=0.20 \mathrm{~N},[\mathrm{Ce}(\mathrm{ClO} 4) 4]$ $=1.25 \times 103 \mathrm{~N}$ 
Energy of Activation $(\Delta \mathrm{E})=19.48 \mathrm{Kcals}$. / mole; Entropy of Activation $(\Delta S)=-3.84$ e.u. and Free energy of activation $(\Delta \mathrm{F})=20.64$ Kcals./ mole.

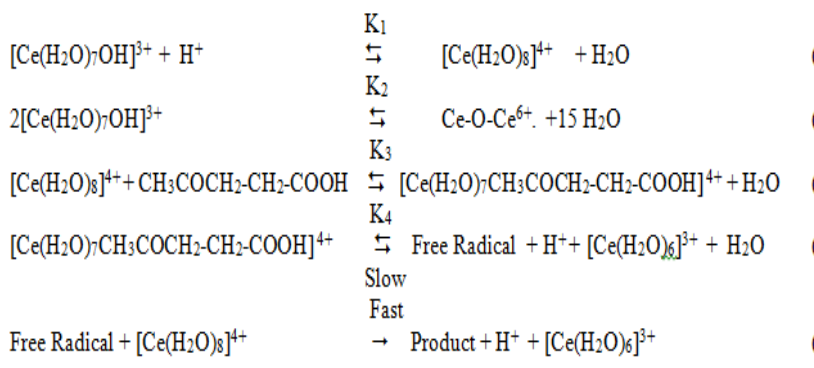

On the basis of the catalytic behavior of $\mathrm{H}+$ and the experimental observations, we propose the following mechanism for the oxidation of levulinic acid.

Equation (4) is the rate determining step. The formation of free radical takes place through $\mathrm{C}-\mathrm{H}$ bond fission which subsequently undergoes further fragmentation [19].

Considering the first order rate dependence on $\mathrm{Ce}(\mathrm{IV})$, the rate equation can be written as,

$-\mathrm{d} / \mathrm{dt}[\mathrm{Ce}(\mathrm{IV})]=\mathrm{k}_{1}[\mathrm{Ce}(\mathrm{IV})] \mathrm{T}$

Where $\mathrm{k} 1$ is the observed velocity constant and [Ce(IV)]T is the total concentration of $\mathrm{Ce}$ (IV) in the reaction.

$[\mathrm{Ce}(\mathrm{IV})]^{\mathrm{T}}=\left[\mathrm{Ce}\left(\mathrm{H}_{2} \mathrm{O}\right)_{8}\right]^{4+}+\left[\mathrm{Ce}\left(\mathrm{H}_{2} \mathrm{O}\right)_{7} \mathrm{OH}\right]^{3+}+\mathrm{Ce}-\mathrm{O}-\mathrm{Ce}^{6+} .+\mathrm{k}_{3}[\mathrm{Ce}$ $\left.\left(\mathrm{H}_{2} \mathrm{O}\right)_{8}\right]^{4+}\left[\mathrm{CH}_{3} \mathrm{COCH}_{2}-\mathrm{CH}_{2}-\mathrm{COOH}\right]$

At a constant hydrogen ion concentration, the concentration of dimeric species will increase with the increase in the initial concentration of $\mathrm{Ce}(\mathrm{IV})$. Thus the concentration of $\mathrm{Ce}-\mathrm{O}-\mathrm{Ce} 6+$ will be a function of initial concentration of $\mathrm{Ce}(\mathrm{IV})$ and hence,

[Ce-O-Ce6+] = f [Ce(IV)]

At lower initial concentration the presence of dimeric species will be negligible and thus from the equation (7) we get, $[\mathrm{Ce}(\mathrm{IV})] \mathrm{T}$

$\left[\mathrm{Ce}\left(\mathrm{H}_{2} \mathrm{O}\right)_{7} \mathrm{OH}\right]^{3+}=$

$$
1+\mathrm{k}_{1}\left[\mathrm{H}^{+}\right]+\mathrm{k}_{1} \mathrm{k}_{3}\left[\mathrm{H}^{+}\right]\left[\mathrm{CH}_{3} \mathrm{COCH}_{2}-\mathrm{CH}_{2}-\mathrm{COOH}\right]
$$

When the initial concentration of $\mathrm{Ce}(\mathrm{IV})$ is higher, the dimmer will be formed by association of monomeric species as shown in equation (2). Thus the concentration of the $\left[\mathrm{Ce}\left(\mathrm{H}_{2} \mathrm{O}\right)_{7} \mathrm{OH}\right]^{3+}$ will be

$$
[\mathrm{Ce}(\mathrm{IV})] \mathrm{T}
$$

$[\mathrm{Ce}(\mathrm{H} 2 \mathrm{O}) 7 \mathrm{OH}] 3+=\ldots \ldots$

$1+\mathrm{kl}[\mathrm{H}+]+\mathrm{kl} \mathrm{k3}[\mathrm{H}+][\mathrm{CH} 3 \mathrm{COCH} 2 \cdot \mathrm{CH} 2 \cdot \mathrm{COOH}]+\mathrm{K}^{\prime} f[\mathrm{Ce}(\mathrm{IV})]$

less and the denominator in equation (9) will become higher and the following equation will represent the concentration of $\left[\mathrm{Ce}\left(\mathrm{H}_{2} \mathrm{O}\right)\right.$ $k 4 k 3[\mathrm{H}+][\mathrm{CH} 3 \mathrm{COCH} 2-\mathrm{CH} 2-\mathrm{COOH}]$

$\mathrm{kl}=\ldots$

$1+\mathrm{k} 1[\mathrm{H}+]+\mathrm{kl} \mathrm{k} 3[\mathrm{H}+][\mathrm{CH} 3 \mathrm{COCH} 2-\mathrm{CH} 2-\mathrm{COOH}]+\mathrm{K}^{\prime} \mathrm{f}[\mathrm{Ce}(\mathrm{IV})]$

$\left.{ }_{7} \mathrm{OH}\right]^{3+}$,

$\frac{1}{k 1}=\frac{1+K^{\prime} f[\mathrm{Ce}(\mathrm{IV})]}{k 4 k 3[\mathrm{H}+]}+\frac{\mathrm{K} 1}{\mathrm{k} 4 \mathrm{~K} 3} \frac{1}{[\mathrm{CH} 3 \mathrm{COCH} 2-\mathrm{CH} 2-\mathrm{COOH}]}+\frac{\mathrm{K} 1}{\mathrm{~K} 4}(12)$

Where $\mathrm{K}^{\prime}$ is a constant.

Considering the equation 1, 3, 4 and (10) we get,

Or

Accordingly, at constant $\left[\mathrm{H}^{+}\right]$and $[\mathrm{Ce}(\mathrm{IV})]$, the graph of $1 / \mathrm{k}_{1}$ against $1 /\left[\mathrm{CH}_{3} \mathrm{COCH}_{2}-\mathrm{CH}_{2}-\mathrm{COOH}\right]$ will be a straight line, cutting an intercept from the $1 / \mathrm{k}_{1}$ - axis. The plot of $1 / \mathrm{k}_{1} \mathrm{vs.1/}\left[\mathrm{H}^{+}\right]$will also be linear at the constant [Levulinic acid] and [Ce (IV)].

At lower initial concentration of $\mathrm{Ce}$ (IV) the dimeric species will be negligible and hence the value of rate constant will be higher as compared to higher initial concentration of $\mathrm{Ce}$ (IV) where the dimeric species will be significant. However, this has been observed that the value of $k_{1}$ does not increase in a given run, may be because of the slow reversibility of the equation (2). This effect is reminiscent to that mentioned in the literature with regards to the oxidation of alcohol [20], aldehydes [21] phenanthrene and 3substituted phenanthrene [22] by chromic acid where acid chromate-dichromate dimerisation equilibrium arises that the value of first order rate constant does not alter during the run but changes with the initial concentration of the oxidant.

\section{Stoichiometry and products}

In the studies of kinetic runs, the concentration of $\mathrm{Ce}$ (IV) was kept less than the concentration of levulinic acid but in the stoichiometric study, a known excess of $\mathrm{Ce}$ (IV)-perchlorate was allowed to react completely with a mixed amount of levulinic acid at $30^{\circ} \mathrm{C}$. The reaction takes three months for its completion as observed from time to time estimation of $\mathrm{Ce}$ (IV). The stability of $\mathrm{Ce}$ (IV) solution for this duration was tested and found that the concentration does not alter if the identical conditions were maintained. The unreacted $\mathrm{Ce}(\mathrm{IV})$ was estimated volumetrically and the stoichiometric ratios are given in Table-4.

Table 4- Stoichiometric Ratios

\begin{tabular}{|lll|}
{$\left[\mathrm{Ce}\left(\mathrm{ClO}_{4}\right)_{4}\right] \times 10^{2} \mathrm{~N}$} & {$\left[\right.$ Levulinic acid] $\times 10^{3} \mathrm{M}$} & {$[\mathrm{Ce}(\mathrm{IV})] /[$ [Levulinic acid] } \\
\hline 1.67 & 1.00 & 13.97 \\
2.00 & 1.00 & 14.28 \\
2.50 & 1.00 & 14.39 \\
& Average value of equivalents $=$ & 14.21 \\
\hline
\end{tabular}

The product formed was identified to be acetic acid by ascending paper chromatography with authentic samples using n-butanol saturated with ammonia as a developing solvent and bromophenol blue as a spraying reagent. The $R_{\mathrm{f}}$ value was found to be 0.61 .

On the basis of the equivalents and the product formed, the reaction can be shown to proceed as follows. One moles of levulinic acid gives rise to one mole of acetic acid and 3 mole of carbon dioxide.

$\left[\mathrm{CH}_{3} \mathrm{COCH}_{2}-\mathrm{CH}_{2}-\mathrm{COOH}\right]+14 \mathrm{Ce}(\mathrm{IV})+5 \mathrm{H}_{2} \mathrm{O} "\left[\mathrm{CH}_{3} \mathrm{COOH}\right]+$ $3 \mathrm{CO}_{2}+14 \mathrm{Ce}(\mathrm{III})+14\left[\mathrm{H}^{+}\right]$

\section{Acknowledgement}

The one of authors Rajesh Shukla is highly thankful to University Grants Commission, for financial assistance.

\section{References}

[1] Hanna S.B., Fenton J.T. (1983) Int. Jour. Chem. Kinetics, 15 (9), 925-940.

[2] Calvarusu G., Cavasino F.P., Sbriziolo C. (1981) Int. Jour. Chem. Kinetics, 13(2), 135-148.

[3] Nagarajan S., Srinivasan K.S.V. (1998) Jour. Macromolecular Science, 38(1), 53-76.

[4] Dash S., Patel S., Mishra B.K. (2009) Tetrahedron, 65, 707739. 
[5] Kumar D., Rani A., Prasad D.S.N., Gupta K.S. (1991) Reaction Kinetics and Catalysis Letters, 43(1)133-141.

[6] Scagliarini G. (1926) Atti. Accad. Lincei, (6) 4, 204.

[7] Murchi L.E., Fernelius W.C., Mc Reynolds J.P. (1943) J. Am. Chem. Soc., 65, 329.

[8] Wolf L., Barnighausen H. (1960) Acta Cryst., 13, 778.

[9] Hoard J.L., Silverton J.V. (1963) Inorg. Chem., 2, 235.

[10]Baker H.R., O' Rear J.G., Sniegaski P.J. and Kagarise, R.E. (1961) U.S. Naval Res. Lab. Rept., 5641.

[11]Penny W.G., Anderson J.S. (1937) Trans. Faraday Soc., 33, 1363.

[12]Sherill M.S., King C.B. and Spooner R.C. (1943) J. Am. Chem. Soc., 65, 170.

[13]Duke F.R., Parachen R.F. (1956) J. Am. Chem. Soc., 78, 150.

[14]Evans M.G., Uri N. (1950) Nature, 166, 602.

[15]Baker F.B., Newton T.W. and Khan M. (1960) J. Phys. Chem. Ithaca, 64, 109.

[16]Heidt L., Smith M. (1958) J. Am. Chem. Soc., 70, 2476.

[17]Hardwick T.J., Robertson E. (1951) Can. J. Chem., $29,818$.

[18]King E.L., Pondow M.L. (1952) J. Am. Chem. Soc., 74, 1966.

[19]Ardon M. (1957) J. Chem. Soc., 1811.

[20]Mc Auley A. (1964) J. Chem. Soc., 4054.

[21]Paquetti D., Zador M. (1968) Can. J. Chem., 46, 2507.

[22]Novik A., Westheimer F.H. (1943) J. Chem. Phys., 11, 506.

[23]Wiberg K.B., Mill T. (1958) J. Am. Chem. Soc., 80, 3022.

[24]Narayanankutty N., Bhatt M.V. (1971) Tetrahedron Letters, $24,2121$. 